Article

\title{
The Entanglement of Class, Marriage and Real Estate: The Visual Culture of Egypt's Urbanisation
}

\author{
Mennatullah Hendawy ${ }^{1,2,3, *}$ and Jörg Stollmann ${ }^{1}$ \\ ${ }^{1}$ Chair of Urban Design and Urbanization, TU Berlin, 10623 Berlin, Germany; \\ E-Mails: mennatullah.m.hendawy@tu-berlin.de (M.H.), stollmann@tu-berlin.de (J.S.) \\ 2 Leibniz Institute for Research on Society and Space, 15537 Erkner, Germany \\ ${ }^{3}$ Department of Urban Planning and Design, Ain Shams University, Cairo, Egypt \\ * Corresponding author
}

Submitted: 15 March 2020 | Accepted: 20 June 2020 | Published: 26 June 2020

\begin{abstract}
A majority of scholars consider Egypt's urban development a product of the neo-liberal political economy facilitated by the country's central government. In this article, we want to shift our attention towards the public and its demand for housing. We describe the urban everyday experiences of a population within a country in which a visual culture established via public media creates an urban imagination that does not reflect the lived social, spatial, and economic reality of the majority of the population. Exploration of the general public's attitudes towards media narratives that focus their advertisement campaigns on high class residential projects launched this investigation. The argument that follows is based on empirical studies within the Greater Cairo Region (GCR). In this setting, a puzzling trend from our collected data guides our central research question: Why aren't ads for luxury housing-a market segment clearly beyond the reach of most Egyptians-condemned by those who cannot afford it? To tackle this phenomenon, we shed light on how the pre-and post-marital demand for housing among young couples and their families influence the market, and particularly, the market for upscale and luxury housing in Cairo. The research consists of four phases, including (1) field interviews with Uber and Careem drivers, (2) an online survey targeting inhabitants across varying urban and social segments of the GCR, (3) the first author's personal story, which posits that marriage culture acts as a key driver for real estate narratives, and (4) a visual analysis of a real estate advertisement. To conclude, the article discusses how far a hegemonic visual culture that caters to socio-economic links between class, marriage, and real estate engages the support of a large part of the population, which in turn, co-produces a spatially unjust urban development scheme that works against their own interests.
\end{abstract}

\section{Keywords}

Cairo; class; Egypt; housing; marriage; media; real estate; urbanisation; visual culture

\section{Issue}

This article is part of the issue "Visual Communication in Urban Design and Planning: The Impact of Mediatisation(s) on the Construction of Urban Futures" edited by Gabriela Christmann (Leibniz Institute for Research on Society and Space, Germany), Christoph Bernhardt (Leibniz Institute for Research on Society and Space, Germany) and Jörg Stollmann (TU Berlin, Germany).

(C) 2020 by the authors; licensee Cogitatio (Lisbon, Portugal). This article is licensed under a Creative Commons Attribution 4.0 International License (CC BY).

\section{The Visual Culture of Egypt's Urbanisation}

A majority of scholars consider Egypt's urban development a product of the neo-liberal political economy, which the country's central government has helped facilitate (Dorman, 2007, 2013; Nada, 2014; Yacobi \&
Shechter, 2005). Egypt's professional urban development discourses and practices as well as its planning education focus on satellite towns, prestigious new desert cities, and gated communities catering to the uppermiddle class (Hendawy, in press-a; Hendawy \& Saeed, 2019). These projects are guiding infrastructural invest- 
ments, tying up planning resources and most of all, they are overshadowing the reality experienced by the disadvantaged majority urban population. Although these new city projects, often located in the desert, dominate media narratives in urban development, they have only succeeded in developing around $2 \%$ of the inhabited land mass (Shawkat \& Hendawy, 2016), despite initial plans to increase inhabited density by approximately $32 \%$. According to the World Bank (2008) the total population of the new cities in 2006 constituted approximately $2.5 \%$ of Egypt's urban population. These numbers reflect the fundamental spatial injustice of the country's urbanization schema (see Abotera \& Ashoub, 2017; Hendawy, 2015; Ibrahim \& Singerman, 2014).

A majority of scholars identify state-led neoliberal reforms of housing supply as the cause (i.e., Elmouelhi, 2019; Hassan, 2017), however, the experience of traversing and living in the city provides an alternative story. In a way, media play a role in conditioning the desires of the general public for luxury housing, despite the fact that it doesn't serve their housing needs. To reach targeted customers, various private and public media channels are used to promote new housing units through commercials, street billboards, SMS messages, press ads, and the like. Although these channels target a minority of the population, the general public becomes exposed to it on a daily basis. To reflect on this issue, we define the visual culture of Egypt's urbanization as one that is highly mediatized, which produces virtual and physical urban realities following Rose (2001), Rose, Degen, and Melhuish (2014) and Watson's (2015, 2016, 2020 [in this thematic issue]) analysis that real estate visualizations have agency in the generation of urban assemblages. The two subsequent images are examples of real estate advertisement, one portraying billboards at a Cairo road (Figure 1) and the other being a real estate ad on one of the developer's Facebook page (Figure 2). Another research by the first author shows that the majority of real estate ads in street billboards are in English (see Hendawy, in press-b).

Accordingly, we want to shift the attention towards the public and its demand for housing. Our article demonstrates the urban everyday experiences of a population in a country in which a visual culture established via public media creates an urban imaginary that does not match the lived social, spatial, or economic reality of the majority of the population (Hendawy, in press-b; Hendawy \& Saeed, 2019). Exploration of the general public's attitudes towards media narratives that focus their advertisement on high class residential projects launched this investigation. We base our arguments on empirical studies in the Greater Cairo Region (GCR). The Greater Cairo Region consists of Cairo Governorate, Giza Governorate, and parts of Qalyubia Governorate, with a total population of around 18 million as of 2006 (Bush \& Ayeb, 2012). In this setting, a puzzle from our collected data guides our central research question: Why aren't ads for luxury housing-a market segment that

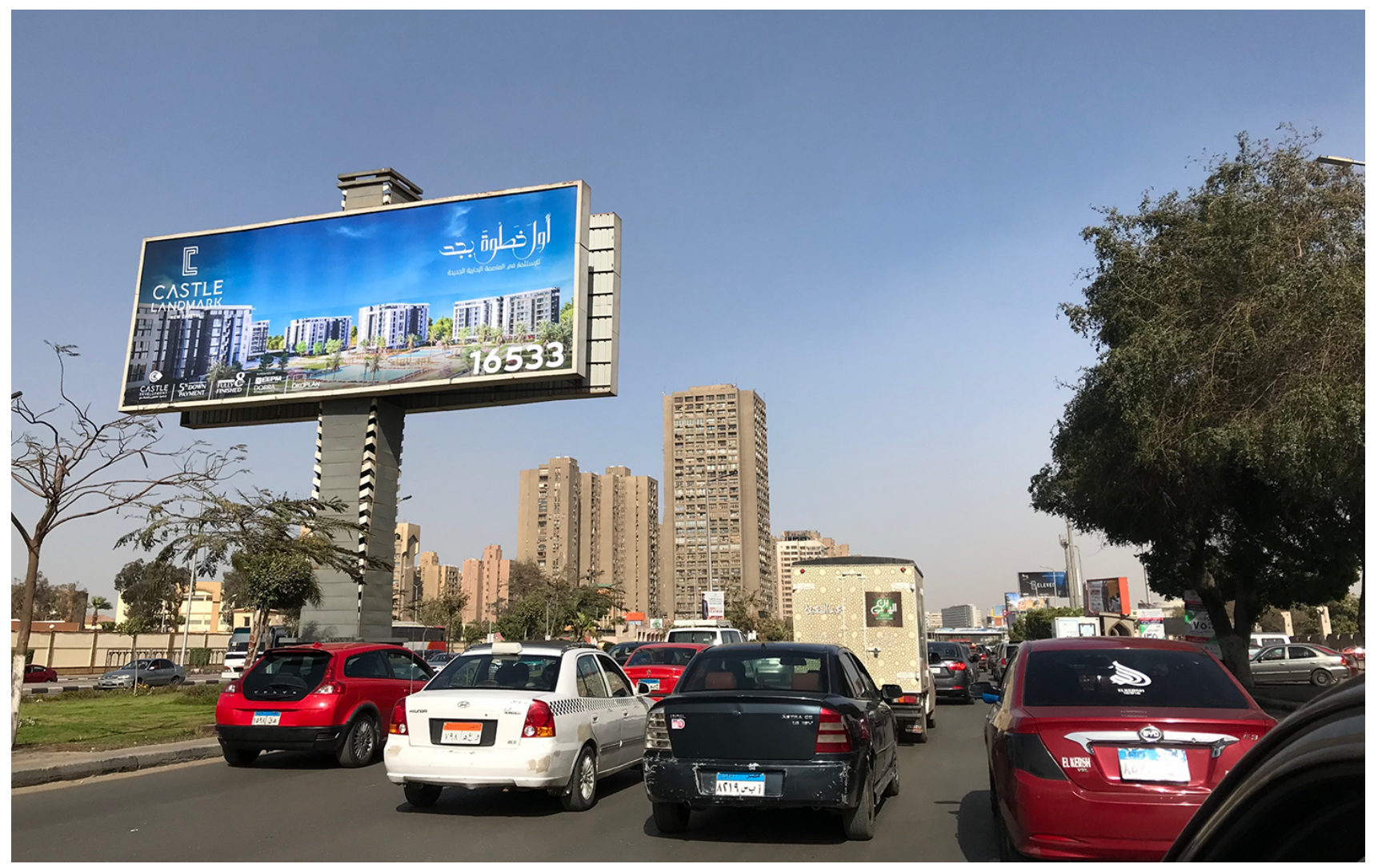

Figure 1. Two billboards on Salah Salem road in Cairo. Source: Hendawy \& Saeed (2019). 


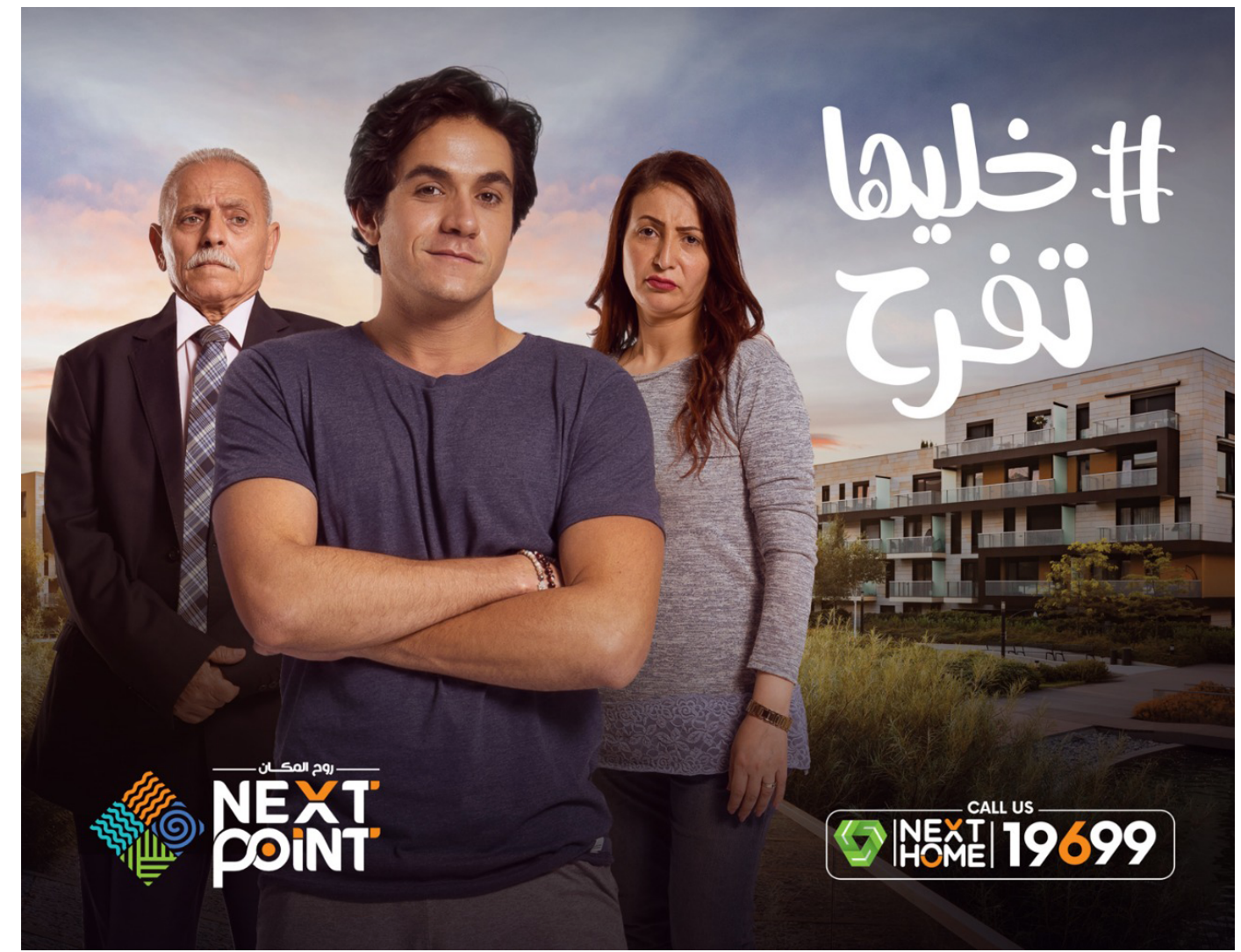

Figure 2. Photo from Cairo's real estate street billboards (translation: Make her happy). Source: Next Home Egy (2019).

caters beyond the reach of most Egyptians - condemned by those who cannot afford it? The pervasiveness of realestate advertisement could be interpreted from (1) the government's perspective and its desire to promote its political agenda manifested through its urban planning schemes, but also from (2) a bottom-up cultural perspective, which functions as an indicator of the general public's demands or least desires. The former reflection was shared amongst a number of scholars (Daher, 2013; Denis, 2006; Elmouelhi, 2019; Hassan, 2017; Shawkat \& Hendawy, 2016), while the latter postulate remains under-explored. Accordingly, our research addresses the following question:

How do the exclusive illusionary narratives of urban futures remain so omnipresent and indelible in the Egyptian imagination, despite the fact that the majority of the urban population lacks the tangible means of living that experience and does not benefit from the products advertised?

We will answer this question by shedding light on how the pre- and post-marital demand for housing among young couples and their families influence the market, particularly the market for upscale and luxury housing in Cairo. The article starts by laying out the theoretical framework and expounding our positionalities that underpin the study on the classed visual culture of real estate advertisement and development in Egypt.
Subsequently, the article elaborates on the methodological framework as it pertains to each of the four phases of empirical research that constitute the study. These research phases include (1) field interviews with Uber and Careem drivers, (2) an online survey targeting inhabitants across urban and social segments of the GCR, (3) autoethnography of the first author's personal story of looking for an apartment when getting married, and (4) visual-cultural media analysis. To conclude, the article discusses how far a hegemonic visual culture that caters to and socio-economic links between class, marriage, and real estate engage the support of a large part of the population, which in turn, co-produces a spatially unjust urban development scheme that works against their own interests.

\section{Neoliberalism from an ANT Perspective}

Egypt's centralised planning system facilitates marketdriven development through laws, which foster close cooperation between governmental planning institutions and privatized building and real estate sectors (Ansari, 2011; Dorman, 2007, 2013; Ibrahim \& Singerman, 2014; Hamilton et al., 2012; Serag, 2015; Sims, 2003; World Bank, 2007). Additionally, Egypt's neoliberal urban governance is marked by its lack of legal protections for the urban poor and their right to housing. In short, the present planning scheme is market-based and controlled by the government (see Elmouelhi, 2019; Hassan, 2017; Nada, 
2014). The real estate sector, one of the largest markers in Egypt, can be considered a product of this neoliberal planning system. In the beginning of the fiscal year 2010-2011 this sector became the second largest recipient of public and private investments (Hassan, 2017). The investment law No. 72 of 2017, issued in May 2018, offered incentives and tax reductions for private sector investments in underdeveloped parts of the country (Nabil, 2019; Xinhua, 2019). Within this legal context, it's clear that the real estate market relies upon strong public-private partnerships; however, most of the constructed and promoted projects cater only to upper classes (see Hassan, 2017; Metwally \& Abdalla, 2011), who account for just $14.1 \%$ of Egyptians (Nabil, 2019). Symptomatically, media channels are dominated by advertisements for projects that prioritize this minority social class (see Haas, 2019; Hendawy, Riad, \& Elgerdly, in press; Howard, 2019; Rose et al., 2014). Investments in affordable housing for lower income classes is considered risky for developers who seek high profit margins, and given the fact that the government's neoliberal urban policies encourage and promote the construction of luxury housing, the private sector's inclinations are more partial towards investing real estate projects of this kind (Elmouelhi, 2019); simultaneously, media narratives and visuals showcase real estate projects that are unattainable to most of Egypt's inhabitants. These two objects of research-the political economy and the visual culture of advertisement-inspire the theoretical framework of this research: critical neoliberal urban theory (coined by Daher, 2013; Denis, 2006; Harvey, 2005; Pettit, 2019) and the agency of non-human actants (actor network theory), with a focus on a visual culture discourse, which highlights the agency and impact of visual representations on urban development (i.e., Collins \& Kearns, 2008; Degen, Melhuish, \& Rose, 2001; 2015; Merche \& Lamprou, 2016; Rose et al., 2014). The combination of these theoretical approaches requires a short explanation.

In his article "The Politics of Urban Assemblages," Ignacio Farías (2011) differentiates between critical urban studies (i.e., neoliberal urbanism) and the tracing of urban assemblages within an actor network theory framework. He bases the distinction on four theoretical and methodological aspects: "the style of cognitive engagement (inquiries or critique), the definitions of the object of study (cities or capitalism), the underlying conceptions of the social (assemblages or structures), and the envisaged political projects (democratization or revolution)" (Farías, 2011, p. 365). He states that:

The central question we need to pose is whether we study cities as an instance of something else, of capitalism (and neoliberalism) in this case, or we engage in an inquiry into the city and urbanisation as a positive, actual and self-entitled process." (Farías, 2011, p. 368)

We follow Farías in taking a critical stance towards explaining Egypt's urbanisation exclusively via neoliberal governance; framed otherwise, our objective is to disentangle the social and cultural factors-explicitly from the media - that stabilize these policies. In our article, we utilize the perspectives of Gillian Rose, Monica Degen, and Clare Melhuish, who argue that computer-generated images that communicate and market real estate projects are "a new form of visualizing the urban...instead of approaching them as images situated in urban space, their digitality invites us to understand them as interfaces circulating through a software-supported network space" (Rose et al., 2014, p. 386). Finally, in order to examine the role of class as a dominating factor in the network of visuality, we engage with the work of Haraway (1991) who "argues that particular forms of visuality produce particular visions of social difference and that institutions, such as capitalism, mobilize certain forms of visuality to see, and to order, the world" (Aitken, 2009, p. 3).

By adopting an ANT perspective on the actornetwork of the visuality of urban governance, we are stepping away from studying Cairo in order to study neoliberalism; we want to understand the development of Cairo as a process of interaction, in which neoliberal governance is only one of the many co-producing factors. In doing so, we gain perspective on the potential power of the general public as actors within a network that coproduces the urban in Egypt. Consequently, our research entails an inquiry into the distribution of this agency.

\section{Authors' Positionalities}

Our positionalities as authors are crucial elements that construct this study's investigation and methodology. The study's topic-its underlying assumptions and preconceptions-are biased due to our own personal experiences and positions in the world. Thus, we-two upper middle-class academics and urban researchers from Egypt and Germany, respectively-reflect on these positions in the forefront of this study. Mennatullah Hendawy's personal experience with house hunting in Cairo is integrated as an autoethnographic story (Adams, Jones, \& Ellis, 2014), which emphasises the power of internalised cultural values and applies our argument concerning the entanglement of class, love, and real estate. We engage with Della Pollock's $(2007,2009)$ work on the use of personal experiences in scholarly writing, namely her proposal of a "performative I" (Pollock, 2007). The declared subjectivity reflects the various discussions that we had during and between the four research phases and where the second author, Jörg Stollmann, who lacked familiarity with Cairo's everyday reality, both supported and critically reflected the first author's personal and scholarly knowledge. We do not conceive of the shared story as valuable because it should be read as 'authentic' or 'true,' but rather, as a way to reflect how this subjectivity could-even in a fictional sense-still discuss the engagement of the individuum within a cultural context as a process of struggle and disconcertion. Lastly, in order to acknowledge the multiple, distinct realities that we ex- 
perienced as researchers along with those from participants in the field, we engage in critical reflexivity (Attia \& Edge, 2017; Mills, Durepos, \& Wiebe, 2010) to highlight cultural and class differences as well as to generate a critical discussion of the data and findings. To do so, data is collected from multiple sources and participants as presented in the methodological frameworks.

\section{Methodological Framework}

In order to explore the effects of the schism between the visual representation of exclusive real estate projects via advertisements and the physical urban realities experienced by most of the population, this research follows a mixed-method approach and applies an abductive reasoning mode within the framework of critical neoliberal urban discourse and ANT, as presented above.

Abduction is "a notion developed by Aristotle in his Organon (1995) and later resumed by Peirce (1956)." It is "conceptualized as making guesses" (Philipsen, 2017, p. 45). Dubois and Gadde (2002) explain that utilizing abduction in a study entails that:

The original framework is successively modified, partly as a result of unanticipated empirical findings, but also of theoretical insights gained during the process. This approach creates fruitful cross-fertilization where new combinations are developed through a mixture of established theoretical models and new concepts derived from the confrontation with reality. (p. 559)
Accordingly, abduction is useful in this study, as it helps address the research question and it allows for the possibility of 'making a guess' regarding the entanglement of marriage, class, and real estate.

The research constitutes four phases of data collection and analysis, which targets several groups within the general public. Nevertheless, we are aware that the represented public in this study is only an indicative part of the general public. To help mitigate this aspect, each phase sought to include different sub-publics within. The four research phases of the study include: (1) unstructured interviews with Uber and Careem drivers, (2) an online survey targeting the general public, (3) the first author's personal story of searching for an apartment in Cairo when she got married, and (4) the visual story analysis of a sample of real estate advertisement. Throughout the article, we will present in detail how and why each method is conducted along with the research findings. In summary, the Table 1 presents the research phases and the collected data, which also reflects the structure of the rest of the paper.

\subsection{PHASE 1/Interviews with Drivers: Few Feel Addressed by Real Estate's Advertisements...}

The first data collection phase started in May 2019 with interviews from Uber and Careem drivers in the GCR regarding their perceptions of real estate advertisements in the GCR. Careem and Uber are both an app-based taxi service, however, Careem also includes cars from normal Egyptian taxi drivers with their cars. The Careem

Table 1. The mixed-method research methodology.

\begin{tabular}{|c|c|c|c|c|}
\hline \multirow{3}{*}{$\begin{array}{l}\text { Methodology } \\
\text { Phase and } \\
\text { Time }\end{array}$} & \multicolumn{4}{|c|}{$\begin{array}{l}\text { Mixed-method approach and an abductive reasoning mode within the framework critical neoliberal } \\
\text { urban discourse, STS, and ANT }\end{array}$} \\
\hline & 1 & 2 & 3 & 4 \\
\hline & May 2019-June 2019 & September 2019 & November 2019 & December 2019 \\
\hline $\begin{array}{l}\text { Method and } \\
\text { Data }\end{array}$ & $\begin{array}{l}\text { Unstructured } \\
\text { interviews with } \\
20 \text { Uber and Careem } \\
\text { drivers and } \\
16 \text { representatives } \\
\text { of middle and upper } \\
\text { classes }\end{array}$ & $\begin{array}{l}\text { Online survey that targeted } \\
120 \text { respondents yet attracted } \\
228 \text { responses, which were further } \\
\text { divided in terms of their locale, } \\
\text { with } 112 \text { inhabitants of the old } \\
\text { city }(49.56 \%), 49 \text { inhabitants of } \\
\text { suburbs }(21.68 \%), 35 \text { inhabitants } \\
\text { of gated communities ( } 15.49 \%) \\
\text { and } 30 \text { inhabitants of informal } \\
\text { areas }(13.27 \%)\end{array}$ & $\begin{array}{l}\text { Autoethnography } \\
\text { of the personal } \\
\text { story of the first } \\
\text { author }\end{array}$ & $\begin{array}{l}\text { Visual analysis of } \\
\text { a real estate } \\
\text { advertisement } \\
\text { that showcases } \\
\text { the entanglement } \\
\text { of class, marriage } \\
\text { and real estate }\end{array}$ \\
\hline $\begin{array}{l}\text { Analysis and } \\
\text { interpretation }\end{array}$ & Thematic analysis & Quantitative survey analysis & Autoethnography & Visual analysis \\
\hline $\begin{array}{l}\text { The group of } \\
\text { the general } \\
\text { public (micro } \\
\text { public) }\end{array}$ & Working class & $\begin{array}{l}\text { Sub-publics living in different } \\
\text { parts of the city (Old city, } \\
\text { suburbs, gated compounds, } \\
\text { informal areas) reflecting } \\
\text { the different spatial and } \\
\text { socio-economic conditions }\end{array}$ & $\begin{array}{l}\text { Middle class, } \\
\text { female, recently } \\
\text { married }\end{array}$ & $\begin{array}{l}\text { Audience of } \\
\text { TV ads }\end{array}$ \\
\hline
\end{tabular}


drivers interviewed in this study are all drivers of the normal state-induced white taxi. The drivers presented in this study represent a sub-public that is able to access various parts of the city on a daily basis. Drivers were also included in this research because they reflect the views of the working class since most of the interviewed Uber/Careem drivers are not owners of the car, but rather appointed by the car owners. Over the course of about a month, 20 unstructured interviews were conducted (50\% Uber drivers and 50\% Careem drivers, all the interviewees were males except one female driver). Drivers of Uber and Careem were chosen over normal taxi drivers for safety and accessibility reasons. We would like to acknowledge that the inspiration to utilize the conversations with drivers in this study stems from the novel from Khaled el Khamisy (2007), Taxi. Cabbie Talk, in which he shares 58 short stories with taxi drivers in Cairo concerning a broad range of topics. In general, we found drivers in Egypt to be friendly; indeed, many regularly initiated conversations with their passengers.

The interviews were conducted as casual conversations in Arabic while the first author was using the service. A set of open-ended questions was prepared in advance; however, questions were allowed to emerge organically based on the answers provided. The interviews usually started by pointing out a street billboard that advertised a new gated compound (a sample of what was pointed to while interviewing the drivers is presented in Figure 1). Afterwards, the first author proceeded to introduce herself as well as the study being conducted and asked the drivers about their age along with where they live. These inquiries were followed up with further questions, a sample of which is provided in Table 2. In general, questions sought to gather information in four key areas: current living conditions, future housing aspirations, planning culture in Egypt, and media-planning related aspects. Notetaking took place in parallel to the conversations and were later reorganized into tables to prepare the responses for thematic analysis. Eventually, the data used in this article was translated to English.
Reflecting on the first author's position as an interviewer, we are aware that the female gender as well as the action of informing the drivers of her student status enabled her to access the field as sympathy and trust were established. However, her habitus and the parts of the city she went to and from still clearly identified her as an upper-middle class-citizen to the drivers, which might have elicited certain responses.

As evaluated from our data, the drivers appeared to possess a diverse range of opinions regarding real estate advertisements in Cairo. Some drivers viewed them as a mere technical activity reserved only for marketing purposes, while some drivers found them "provocative" (meaning "revolting or "upsetting"; in Arabic مستفز). At the same time, other drivers mentioned they neither care nor recognize real estate ads, which was an astonishing answer given their visual omnipresence.

For example, one of the drivers, 39-year-old male, living in an informal area (unregistered and/or unplanned area) said "I will not look at an advertisement like this because it is already out of my budget and they speak about millions." Another driver (40-year-old male, living between a historical neighbourhood and an informal area) directed the discussion towards the general dichotomy between media generated images and reality stating that:

I personally access a lot of these promoted compounds and I see in the advertisement something different than what is inside there, maybe because in the advertisement we see a façade, it looks nice. What is included in the advertisement is the scene they wish to have but in reality, this is not the real scene.

Moreover, many drivers mentioned that if there was no financial barrier they would have moved to such promoted areas. Nevertheless, many of them also stated that they did not think that they will feel a sense of belonging in these areas, due to the difference in social standing and lifestyle. Collectively, the views of the

Table 2. Sample of questions discussed with drivers.

\begin{tabular}{ll}
\hline Topic & Description \\
\hline General questions & Age: \\
Gender: & Where do you live and since when? \\
Current home & Would you like to change your home? Y/N \\
& What is your motive/pressure to change (or remain in) your current home? \\
Dream home & Where would you like your home to be located? \\
Planning culture & What are your thoughts on moving to the desert/ or to a new city? \\
& $\begin{array}{l}\text { To what extent do you think you are part of the 'cultivate the desert' dream? } \\
\text { What do you think about gated communities? }\end{array}$ \\
Media-planning culture & What do you think about the real estate advertisements?
\end{tabular}


drivers-as a working-class population-show that a majority are aware of the real estate advertisements, yet very few feel represented by them. Most drivers shared feelings concerning a lack of 'belonging' or inability to afford to live in these housing complexes; as such we interpreted the sense of 'invisibility' felt by drivers in relation to the signs as a reaction to the exclusivity of the product, whether consciously or subconsciously.

\subsection{PHASE 2/Online Survey: ... But the Degree of Acceptance Is Similar among All Socio-Economic Classes...}

Based on the data collected from the first phase, an online survey was developed and distributed in September 2019 targeting a broader segment of the general public, which was further demarcated into four categories based on the location of each respondent's current residence: an old/historical neighbourhood, a suburb, a gated community, or an informal area. This categorization scheme sought to represent the variety of residential locales across the GCR, which, in turn, could be used roughly to reflect the class-stratum of Egyptian society. The survey targeted a sample of 120 inhabitants in Cairo (30 in each neighbourhood category). It succeeded in attracting 228 responses, which were then divided into 112 inhabitants of the old city (50\%), 49 inhabitants of suburbs (22\%), 35 inhabitants of gated communities (15\%) and 30 inhabitants of informal areas (13\%). Nevertheless, it is worth mentioning that even though we tried to acquire inhabitants from all neighbourhoods, the categorization of areas was schematic rather than fine-grained. For instance, Anwar (2009) classifies gated communities in Egypt alone into four categories including: luxurious gated communities, moderate gated communities, lower high gated communities and post enclosed gated communities. However, in the conducted survey, all gated communities are grouped into one category. The online survey, titled 'Housing Dreams in the Greater Cairo Region' consisted of four sections:

I. Demographic characteristics (12 mandatory questions, 1 optional question);

II. Real estate advertisements in the GCR, including a sample of images (9 mandatory questions, 4 optional questions);

III. Current housing situation (3 mandatory questions, 1 optional question);

IV. Preferences for future housing ( 8 mandatory questions, 5 optional questions).

The profile of the respondents can be summarized as follows: $56 \%$ between 25 and 34 years old, 58\% females, $63 \%$ employed full-time, $51 \%$ working in the private sector, $64 \%$ owners of current residences and $53 \%$ car-owners. A limitation in the survey sample can be observed here due to the fact that only around $9 \%$ of Egyptians are car-owners according to the Central
Agency for Public Mobilization and Statistics (CAPMAS, 2016, as cited in Ahram Online, 2017). Even though the sampling aimed at diversifying respondents via their place of residence, the very poor classes still appeared to be missing, since the use of an online survey meant that the sample was limited to those who could read and write as well as those with access to technology in the targeted areas. In general, illiteracy rate in Egypt is estimated to be around 20\% ("Illiteracy in Egypt decreases, but number still high," 2019). Accordingly, respondents to the survey are likely more financially well-off and possess superior digital skills across the four groups.

The survey sought to unearth the attitudes of people living in the GCR towards real estate advertisements and the ways these distinct views influenced the respondents' perception towards current and future housing. Our findings demonstrated that street billboards are the most popular form of real estate advertisement, most respondents are exposed to them in their daily lives (63\%). By comparison, $56 \%$ of the respondents are exposed to such advertisements via social media. Following these forms and figures are advertisements on television, websites, phone/mobile media, and in newspapers, respectively. Additionally, $58 \%$ of the respondents mentioned that they frequently recognize the language used in advertisements, $52 \%$ usually recognize the characters or celebrities featured in the advertisement, and $42 \%$ recognize the advertising slogan.

The survey was also designed to confront the issues of segregation and exclusivity that were raised by the drivers in Phase 1. To accomplish this task, answers of the interviewed drivers in Phase 1 were added to the survey as multiple choice answers to some questions. It is estimated that $63 \%$ of the respondents view real estate advertisements as exclusive, $37 \%$ find them provocative/upsetting, and $28 \%$ find them unrealistic. When asked about their perceptions in relation to support of existing advertisements in the survey, 51\% responded that they extremely agreed that real estate advertisements increase segregation among Egyptians, 29\% responded in extreme agreement that there is too much advertising in the GCR and that it needs to be limited, $18 \%$ found that they felt excluded from the rest of the society, while $14 \%$ did not care about it. Our findings reflect a common perception that the current real estate advertising drives social and spatial segregation.

When asked about their moving plans, those living in informal areas were the ones most willing or planning to move in the near future $(40 \%$ mentioned their willingness to move to suburbs, $32 \%$ to the old city, $21 \%$ to gated communities, and $7 \%$ migrate abroad and/or to other parts of Egypt). Most real estate advertisements present housing options for those who can afford living in more expensive parts of the city, namely gated communities. Accordingly, we took this analysis further and applied it to our observation of the sample distribution by the neighbourhood type and compared it with the data concerning perceptions/satisfaction with the status quo 
of the housing market as represented in the advertisements dispersed across Cairo. In order to understand the acceptance and support for the existing advertising campaign as it relates to real estate, we put forth two questions in our survey, as shown in Figure 3 , which presents responses to both questions in one diagram. Throughout the article 'accepting' of real estate ads is defined as "to give admittance or approval to" while 'support' of real estate ads is defined as "to promote the interests or cause of" (Merriam-Webster, 2020a, 2020b).

Figure 3 shows that all status groups have a similar degree of acceptance/support towards the current state of real estate advertisements in Egypt (which were also perceived as exclusionary narratives in Phase 1). At the start of this phase, we hypothesized that real estate ads promoting exclusive compounds that were unattainable to most would be met with opposition, particularly from those living in informal areas. The survey data shows that the individual's residence, does not affect their degree of acceptance towards real estate ads (World Bank, 2012), despite the fact that nearly all advertisements target the upper classes (those with the means to reside in gated communities).
The finding that the degree of acceptance was similar across class lines was very surprising. Looking at it from a critical neoliberal theory perspective, we would have assumed that individuals comprising poorer segments of society, who perceived and commented upon the exclusionary, segregational elements of both the advertisements and development scheme, would have shown less acceptance. We assumed that real estate ads might have a more powerful sense of agency than initially suspected with regard to influencing the general public's acceptance and support, even if their individual interests were unmet or unrepresented. When discussing the research results, we inferred that cultural and societal codes might play a major role in shaping public acceptance and support.

\subsection{PHASE 3/Personal Story: ... Maybe Because It} Relates to Marriage as the Most Important Set of Social Conventions in Egypt?

The personal story is integrated into the study in order to interpret the data from a socio-cultural perspective. The use of autoethnography (Adams et al., 2014) stimulates

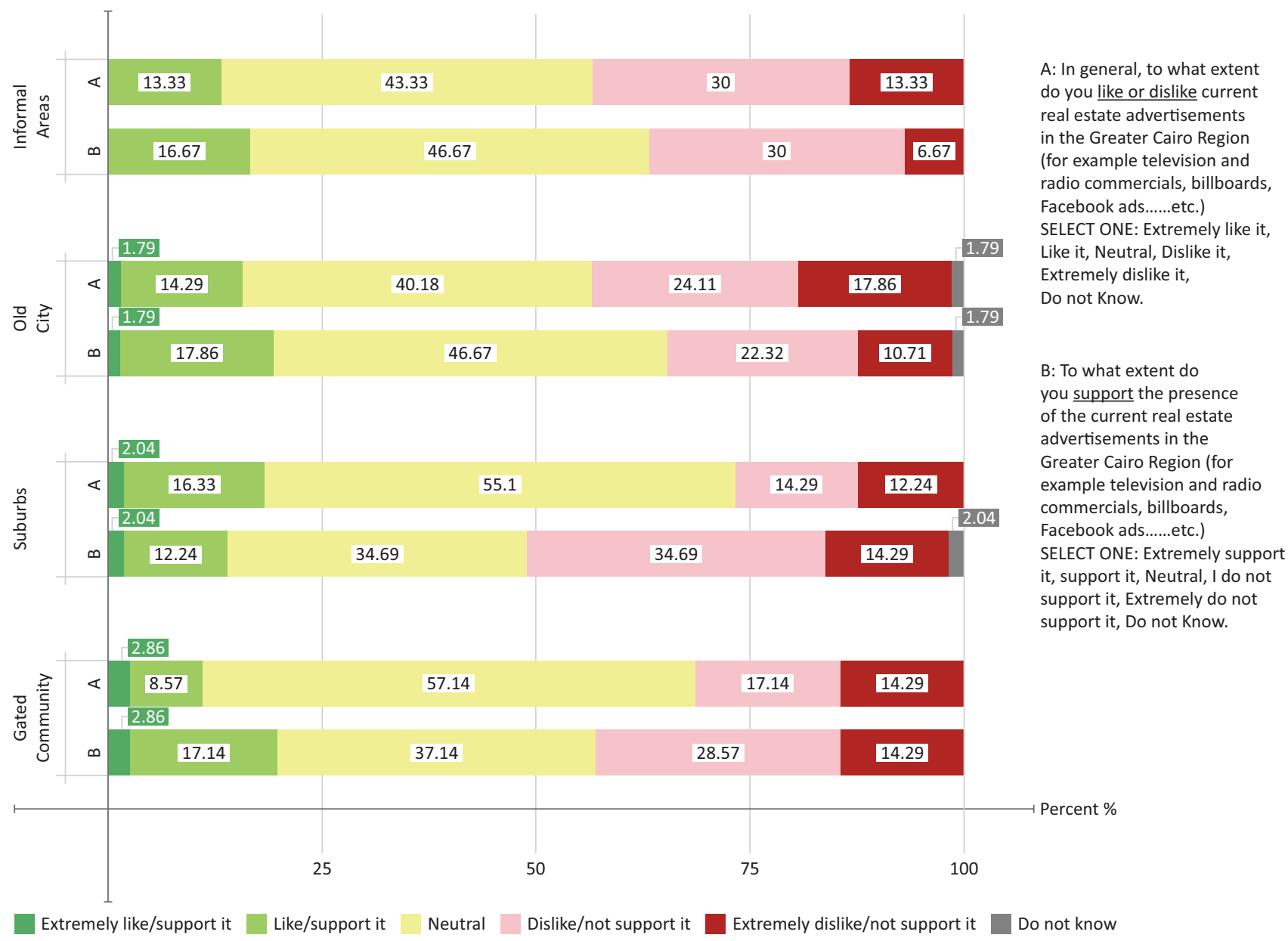

Figure 3. (A) Distribution of the sample by the type of neighborhood and their perceptions/satisfaction about the current real estate advertisements. Source: Author's calculations (Pearson chi2(20) $=11.4971 \mathrm{Pr}=0.932)$. (B) Distribution of the sample by the type of neighborhood and their support of the presence of the current real estate advertisements. Source: Author's calculations (Pearson chi2 $(20)=11.4273 \mathrm{Pr}=0.934)$. 
the discussion of questions related to authority, authenticity, and subjectivity. For our purposes, the authenticity of statements made are of less concern than the process of contextualizing real estate imaginations against the backdrop of local traditions as they relate to love and marriage in Egypt, which compels a deeper examination of the supposed rational and irrational economic desires within particular subjectivities that are rendered highly political:

In 2018, Mohamed and I decided to get married. Though we were both from Cairo originally, we met in Berlin. When we announced that we were getting married, we were instantly faced with the expectations of buying an apartment in Cairo from our relatives, families and even friends, despite the fact that we were living abroad. In Egypt, 'what will people say' is often an important factor in an individual's decisionmaking. Instead of caving to pressure, we postponed our decision and are still searching for 'this apartment.' Over the course of this process we began to question whether or not we truly needed one at all or if we were merely complying with societal codes concerning what makes a good young family, or rather, what makes a young family look good.

In Egypt, the current housing culture is dominated by the practice of owning, not renting. Given that the housing units in 'upper class' areas typically range from 90-250 sqm, a couple that aspires to maintain a high standard of living is left with limited options for living. They can: (a) rent and go against the culture of home ownership, an action that may be unacceptable to parents of the couple, (b) buy an apartment in an area with lower standards and drop out of the privilege cycle. In Egypt, where someone lives often influences the way a person is positioned and viewed in society, which I can also attest to in my own personal experiences. Finally, with option (c) the couple can leave the matter of purchasing an apartment to their parents. In some cases, parents save money over several years or lend money to the couple in order for them to buy an apartment and participate in the marriage decision via their financial control. Indeed, many parents with children from my generation have found real estate to be a safe haven for investing their savings, a practice that l've noticed among my own relatives whose purchased apartments are often left vacant for many years, which may be due in part to the lack of renters in Egypt. Nevertheless, in our case, my husband and I decided to challenge this norm.

As we have searched for an apartment to buy on our own, I must admit that we've limited our search to certain areas in Cairo, which offer more opportunities for upward mobility. However, with our limited budget, we will need to stretch ourselves thin in order to find an apartment in an area appropriate for us and the image of ourselves that we want to create. Our dream apartment is very influenced by a number of (exclusive) societal pressures, which also probably fashion who we are, along with our needs and desires?

In order to develop a conversation surrounding the visual culture(s) of Egypt's urbanization, this personal account captures the way marriage and real estate are entangled with one another, and from a bottom-up cultural perspective. Even if the story reflects an upper-middle class perspective, the cultural and societal conventions are likely applicable to a wider stratum in society. In fact, across the Middle East and North African (MENA) region, it is a common expectation for couples to begin living independently when getting married (Hoodfar, 1997; Singerman, 2007). According to Assaad et al. (2017, p. 2), "achieving independent living at marriage entails a substantial financial investment." In this context, housing represents $38 \%$ of total marriage costs in Egypt; meanwhile an extra $30 \%$ of costs goes to the furniture as the couple prepares the space of their future home (Salem, 2015). Assaad and Krafft (2015) clarify that if someone takes on full financial responsibility and covers the marriage costs from their savings, it would amount to approximately 8 years worth of one's salary for the cost to get married, the initial housing cost alone corresponds to the wages of one partner for around 3 years. Therefore, "securing housing is a crucial component of getting married, and housing is by far the greatest component of the cost of marriage" (Assaad, Krafft, \& Rolando, 2017, p. 2). As such, documented marriage contracts reflect a demand for housing. According to the CAPMAS, 912,606 marriage contracts were recorded in 2017, which implies a demand of nearly half a million units annually (Xinhua, 2019), Similarly, Nabil (2019) points out that "this [demand for real estate that arise from marriage] coupled with the widespread notion of real estate being a safe value, create a strong demand for property, especially in the largest cities."

After examining the findings from Phases 1 and 2 along with the reflections shared in phase 3 , we came to realize that perhaps the exclusionary narratives of real estate in Egypt continue growing and maintaining their power because they have been embedded within the culture of marriage. The aforementioned personal account provides a bridge to Phase 4, which allows us to delve further into societal traditions in Egypt as they relate to class, marriage and real estate. The following section offers a visual analysis on the use of a television advertisement that employs marriage as a theme in promotion of a gated compound.

\subsection{PHASE 4/Visual Analysis of Video Advertisement: House First, Marriage Second!}

Our previous analysis explored the socio-cultural factors underlying the real estate market in Egypt. In our study, 
we noticed that many video advertisements and internet campaigns for housing units include narratives that follow young engaged couples who are apartment-hunting. A popular one comes in the form of a television commercial for the gated compound 'Madinaty' (an Arabic word meaning 'my city'; see also Figure 2). Because commercials are accessible across income and social groups in Egypt, we are able to look at a broader range of society. Television is the most influential source of information in Egypt (Allam, 2018); indeed, according to the Oxford Business Group (2016, para. 4), "television remains the priciest medium for advertising, and with an audience that equates to $95 \%$ of the population on a weekly basis." The Madinaty commercial that was broadcasted in 2019 was selected for its popularity on television as well as on YouTube, where it had over 100,000 total views. It gained widespread attention for its title song from popular Syrian singer, Assala; it was also the source for controversial discussions and ironic comments on the internet as it showcased societal exclusivity (see BBC Arabic News, 2019). Madinaty is an exemplary desert town development of gated communities, shopping districts, and service facilities located in the northeast of Cairo. Madinaty was developed and constructed by the Talaat Moustafa Group and spans over 33,6 mn sqm (Talaat Moustafa Group, 2020), with plans to encompass 120,000 residential units that seek to house around 600,000 inhabitants (Madinaty, 2015). In 2016, the Ministry of Housing sold around 3900 housing units in Madinaty (INVEST-GATE, 2016). According to a phone call with New Cairo government office, the Ministry of Housing owns approximately $7 \%$ of the buildings in Madinaty (personal communication, 2020).

The following images present a series of screenshots from the 2019 Madinaty ad. The commercial, which spans roughly three minutes, starts with a woman overlooking the development of Madinaty. In the frames that follow, she encounters her dream man, her future husband. A reoccurring take shows the woman in a garden surrounded by lush blooming bushes and trees, evoking a dream-like setting. Via montage, the pink flowers from the garden become visually linked to the flowers encompassing the perimeter of Madinaty's golf course. Subsequently, a series of scenes exhibit green open spaces and waterscapes along with aerial views of the compound and images that allude to the facilities that are available for use (i.e., a mosque, schools, sport clubs). Around the middle of the video, a scene of celebration and fireworks over Madinaty appears and is then followed by frames of the woman getting dressed for her wedding and embracing a woman, most likely her mother, before joining her wedding party on the Madinaty premises. A metaphorical scene appears in which the woman enters through a swaying mesh of coloured ribbons; then it is followed with a shot of her touching a baby toe. We see her and her husband holding their new-born and presenting it at a family gathering, which is likely set in their own private garden in Madinaty.
In short: the couple meets at the housing compound, falls in love, buys a house, gets married, has a baby and builds a family. Figure 4 presents an abstract drawing of the analysed TV advertising.

Assala's song says:

We were here, you and me and the adoration. And love is the spring that brings us together, do you remember those days?

You gifted me a necklace from roses, poems of love and Quotes, our initials carved in the trees telling our story to the world and our city's glamour still shining day and night!

Madianty...Madianty...Madianty...Madianty...Madianty...Madianty...Madianty...Madianty...

Beauty and Madinaty are synonyms. Every corner decorated by the golden rays of the sun, the trees, flowers and roses dressing it in every colour. And summer breeze touches us, drawing us above the branches. We look forward to a bright tomorrow that plays us like melodies, darling!

Madianty...Madianty...Madianty...Madianty...Madianty...Madianty...Madianty...Madianty...

Madinaty is my home and orchard, it is my family, people and entity, and life's beauty in a place that is similar to myself and my dreams. It is the habitat of the beloveds and a love nectar that glides through the veins and runs like blood in my arteries.

Essentially, the lyrics' storyline indicates that the couple did not merely meet in Madinaty, but that they were actually married by Madinaty. The video suggests that the compound is endowed with transformative powers, perhaps, even, a sense of agency: to make love and marriage possible, to turn a single woman and man into a loving, independent and happily-married couple. In the ad, the metaphoric value of real estate is heightened to a level where it becomes the force that bestows future love and a fulfilling life. At the same time, the way the couple and the others are dressed, it is clear that the advertisement views its audience as members of the uppermiddle class. The interconnectedness between the urban development trend of luxury satellite towns as well as the marriage-housing narrative reflect a situation in which a top-down approach or politically directed planning paradigm (see Shawkat \& Hendawy, 2016) is reinforced through a culturally coded desire to consume from the bottom-up perspective. The interviews showed that despite the fact that it is both financially and socially out of reach for most Egyptians, living in a gated community has become a common goal. The process of purchasing an apartment before marrying functions as a core responsibility of the husband and his parents, which illus- 

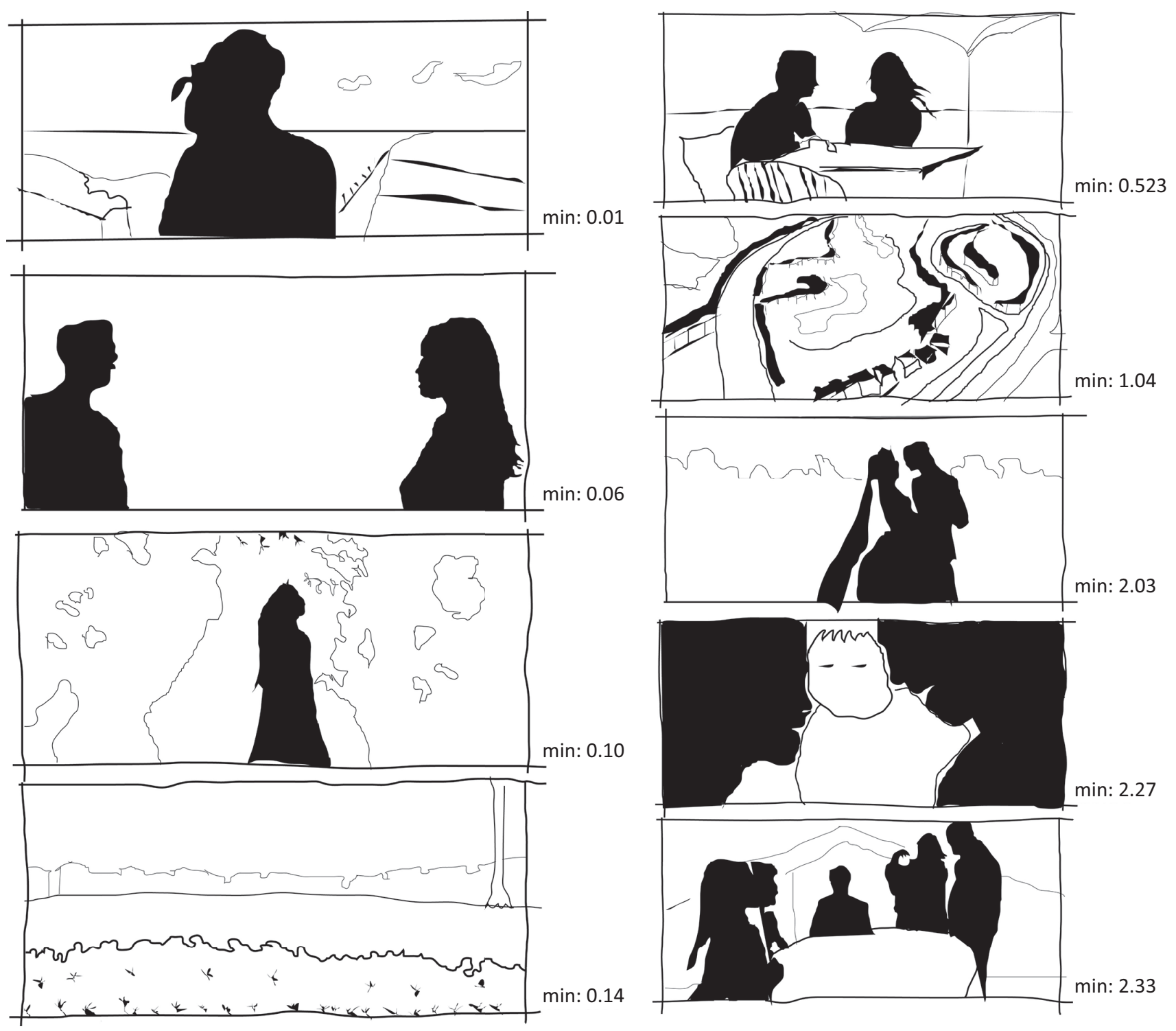

Figure 4. Abstracted screenshots from Madinaty advertisement in order from top to bottom. Source: Hendawy's drawing based on Madinaty advertisement from Sada el Balad (2019).

trates the way in which individual decisions and societal codes become interdependent with one another.

Following the ad's release in May 2019, it received a wave of criticism with regard to the compound's exclusivity for the rich and the song that accompanied the ad was also ridiculed (BBC Arabic News, 2019). While public debate exposed the unintentionally comical aspects of the marriage portrayed in the ad as well as the more serious issues concerning its exclusive, even segregated, narrative, it became evident that there is an underlying assumption in Egyptian society that the procurement of property enables the individual to achieve upward mobility and to lead a more fulfilling life. Further, critical discussions revealed that such overtly classist visuals and motifs employed in these ads are as grounded in cultural conventions surrounding marriage as much as they are in the government's liberalized urban development scheme.

\section{The Entanglement of Marriage, Class and Real Estate in Egypt}

Many of the real estate projects being promoted in Egypt are still under construction and will become available for future housing accommodation; therefore, these commercials functions as a means of generating funding in the projects' earliest phases (Hendawy et al., in press). Since individuals typically do not live alone in Egypt, marriage provides an opportunity to create a new household (Hoodfar, 1997; Rugh, 1984; Shorter \& Zurayk, 1988). Accordingly, this premise sets the stage for interlinking the allocation of housing with marriage. In order to purchase the new apartment or house, a number of financial and societal politics come into play: starting with where the future home will be located to how much it will cost and who will bear the expense (usually, it is the groom or his parents). Class dimensions play a crucial role in 
determining where the future household will be located, and further, in the regulation of expectations of the surrounding neighbourhood community. As such, marriage presents the option of maintaining one's societal status or moving up the social ladder, especially for women (Hoodfar, 1997; Wilson, 1998). Accordingly:

In addition to emotional and social factors, economic considerations are of prime importance in the choice of a marriage partner and in the stipulation of the conditions of a marriage contract, since the material well-being of individuals-particularly women and children-is closely tied to the economic situation of their households. (Hoodfar, 1997, p. 51).

Thus, the couples' and their parents' economic situation are a significant factor that feature in the selection of partners (Hoodfar, 1997).

We started our empirical study with the assumption that there would be deep resentment towards the elite residential parts of the city that were being promoted in real estate advertisements, particularly amongst individuals residing in poorer neighbourhoods. Using a mixed method methodology, we collected data, some of which was conflicting. Although our interviews with drivers demonstrated a common understanding that advertised real estate projects widens the inequality gap in the country, our more extensive survey, which featured a broad range of respondents from across the city, found the opposite: that neither the location of a person's residence nor their socio-economic background influences the degree of acceptance of the real estate advertisements. In fact, the majority exercised a sense of neutrality towards present advertising campaigns; it is worth nothing that while they are exposed to commercial visualizations, they have also seen the advertised content physical materialize into new towns and gated communities. Beginning with a presentation of Cairo's current real estate advertisements and ending with an analysis of a commercial, the article explored the broad visual culture of Egypt's highly mediatized real estate market.

The mediatization of potential real estate opportunities functions as a powerful agent that constructs largely unattainable dreams and intangible desires as they relate to the plight of procuring property. These aspirations are appealing across class lines due to the ways in which they maintain and reinforce societal conventions pertaining to love and marriage; indeed, they operate in this respect to such an extent that homeownership becomes a precondition for marriage, rather than the other way around. Since our base assumption was disproven and we found equal support for the ads amongst different social segments, we find that it would be productive to question the extent to which top-down power structures, e.g., the central government, are responsible for shaping public opinion, and to instead, highlight the ways Egyptians co-develop and co-produce urban and spatial injustice through the examination of their lack of resistance, protest or critique. Current urban development schemes are not merely a product of the heavyhandedness of the centralized state or private developers, but of the public's embrace of such programs. Through its apparent acceptance or neutralization of the topic of real estate and the way the interests and desires of the upper classes are catered to in advertising campaigns, the public appears to have granted power to the state and developers, who will continue to propagate such narratives. To conclude, we would like to recognize this co-production not as a fatum, but rather, as a first step of empowerment. As demonstrated by the ridicule that the Mandinaty commercial received, we hope that this is a sign of more to come in terms of recognizing and questioning the entanglements of class, marriage and real estate, and the way they have fundamentally shaped Egypt's spatial injustice. Perhaps this new-found awareness will inspire new and different modes of co-production, if not something more visionary and transformational.

\section{Acknowledgments}

We would like to thank Ahmed Hassan, Hebatullah Hendawy, Iman Safwat Ahmed, Omar Abutaleb. Rana Riad, Salma Anwar, and Yosra El Sharkawy for offering their time and support at different times of this research. Thanks also to the professional survey team, and all the drivers and the survey respondents who took part in this study. Last but not least, thanks to the anonymous reviewers for their thorough reading of our paper and the insightful feedback.

\section{Conflict of Interests}

The authors declare no conflict of interests.

\section{References}

Abotera, M., \& Ashoub, S. (2017). Billboard Space in Egypt: reproducing nature and dominating spaces of representation. Urban Transcripts, 1(3). Retrieved from http://journal.urbantranscripts.org/ article/billboard-space-egypt-reproducing-naturedominating-spaces-representation-mohamadabotera-safa-ashoub

Accept. (2020a). In Merriam-Webster. Retrieved from https://www.merriam-webster.com/dictionary/ accept

Adams, E., Jones, S. H., \& Ellis, C. (2014). Autoethnography (understanding qualitative research). Oxford: Oxford University Press.

Ahram Online. (2017). 9.4 million licensed vehicles in Egypt: CAPMAS. Ahram Online. Retrieved from http://english.ahram.org.eg/NewsContent/1/64/ 270451/Egypt/Politics-/-million-licensed-vehiclesin-Egypt-CAPMAS.aspx

Aitken, S. C. (2009). The emotional life of maps. International Cartographic Association. Retrieved 
from http://icaci.org/documents/ICC_proceedings/ ICC2009/html/refer/27_2.pdf

Allam, R. (2018). Egypt: Media landscape. Maastricht: European Journalism Centre.

Ansari, M. (2011). Who rules: Governance structure's importance in Cairo's urban planning. Cairo from Below. Retrieved from https://cairofrombelow.org/ 2011/09/21/who-rules-governance-structuresimportance-in-cairos-urban-planning

Anwar, A., (2009). Paradox between public transport and private car as a modal choice in policy formulation. Journal of Bangladesh Institute of Planners, 2, 71-77.

Assaad, R., \& Krafft, C. (2015). An empirical analysis of the economics of marriage in Egypt, Morocco, and Tunisia. In C. Monga \& J. Y. Lin (Eds.), The Oxford handbook of Africa and economics: Policies and practices (Vol. 2). Oxford: Oxford University Press.

Assaad, R., Krafft , C., \& Rolando, D. J. (2017). The role of housing markets in the timing of marriage in Egypt, Jordan, and Tunisia (Working Paper 1081). Egypt: Economic Research Forum.

Attia, M., \& Edge, J. (2017). Be(com)ing a reflexive researcher: A developmental approach to research methodology. Open Review of Educational Research, 4(1), 33-45.

BBC Arabic News. (2019). BBC Trending: Oghnyet e'lan "Madinaty" le'asala tuther mawjat aintiqagat [BBC Trending: The song of "Madinaty"'s advertising for asalah raises a wave of criticism]. Retrieved from https://www.youtube.com/watch?v=5MCjZYCFOhs

Bush, R., \& Ayeb, H. (2012). Marginality and exclusion in Egypt. London: Zed Books Ltd.

Collins, D., \& Kearns, R. (2008). Uninterrupted views: Real-estate advertising and changing perspectives on coastal property in New Zealand. Environment and Planning, 40(2), 914-932.

Daher, R. (2013). Neoliberal urban transformations in the arab city: meta-narratives, urban disparities and the emergence of consumerist utopias and geographies of inequalities in Amman. Environnement Urbain/Urban Environment, 7, 99-115.

Degen, M., Melhuish, C., \& Rose, G. (2015). Producing place atmospheres digitally: Architecture, digital visualisation practices and the experience economy. Journal of Consumer Culture, 17(1), 3-24.

Denis, E. (2006). Cairo as neoliberal capital? In D. Singerman, \& P. Amar (Eds.), Cairo cosmopolitan (pp. 47-71). Cairo: American University in Cairo Press.

Dorman, W. (2007). The politics of neglect in the Egyptian state in Cairo 1974-1998 (PhD dissertation). School of oriental and african studies, University of London.

Dorman, W. J. (2013). Exclusion and informality: The praetorian politics of land management in Cairo, Egypt. International Journal of Urban and Regional Research, 37(5), 1584-1610.

Dubois, A., \& Gadde, L. E. (2002). Systematic combining: An abductive approach to case research. Journal of Business Research, 55(7), 553-560.
El Khamisy, K. (2007). Taxi. Cabbie talk. Cairo: Dar El Shrouk.

El Sayed, E. N. S. F. (2016). Residents' satisfaction at gated communities In Egypt. International Journal of Scientific \& Engineering Research, 7(4), 1185-1196.

Elmouelhi, H. (2019). New administrative capital-Cairo. Power, urban development and social injusticeThe official Egyptian model of neoliberalism. In A. Al-Hamarneh, J. Margraff, \& N. Scharfenort (Eds.), Neoliberale Urbanisierung Stadtentwicklun (pp. 215-254). Bielefeld: Transcript Verlag.

Farías, I. (2011). The politics of urban assemblages. City, 15(3), 365-374.

Haas, A. R. (2019). Building new cities to meet Africa's rapid urbanisation is a risky bet. The Conversation. Retrieved from https://theconversation.com/ building-new-cities-to-meet-africas-rapidurbanisation-is-a-risky-bet-126099

Hamilton, N., Kardoush, D., Ansari, M., Hutchison, M., Jamil, R. R., Al-Sweel, F., . . \& Farooqi, M. S. (2012). Land, legitimacy and governance in revolutionary Cairo. New York, NY: Columbia University.

Haraway, D. (1991). Simians, cyborgs and women: The reinvention of nature. New York, NY: Routledge.

Harvey, D. (2005). A brief history of neoliberalism. Oxford: Oxford University Press.

Hassan, N. S. M. (2017). Between accumulation and (in)security: The real estate industry and the housing crisis in Egypt. Cairo: The American University in Cairo.

Hendawy, M. (2015). Connecting urban policy making and implementation-Case of Maspero, Cairo, Egypt (MsC thesis). Ain Shams University, Cairo.

Hendawy, M. (in press-a). [In]visibilities: The academic city versus everyday cities-Mediatizing planning knowledge in Egyptian universities.

Hendawy, M. (in press-b). Visual communication and the [professional] city: From street billboards to offices of urban planning, case of Cairo. Planning Theory and Practice.

Hendawy, M., Riad, R., \& Elgerdly, S. H. (in press). Visual politics of a mediatized urban age: Tracing what the press news makes visible about urban planning, case of the new administrative capital city in Egypt. Palgrave Communications.

Hendawy, M., \& Saeed, A. (2019). Beauty and the beast: The ordinary city versus the mediatised city: The case of Cairo. Urbanisation, 4(2), 126-134.

Hoodfar, H. (1997). Between marriage and the market, intimate politics and survival in Cairo. Berkeley, CA: University of California Press.

Howard, A. (2019). Are planners partly to blame for gentrification? City Lab. Retrieved from https:// www.citylab.com/equity/2019/03/urban-planninggentrification-capital-city-samuel-stein/585262

Ibrahim, K., \& Singerman, D. (2014). Urban Egypt: On the road from revolution to the state? Governance, the built environment, and social justice. Égypte/Monde 
arabe, 11, 101-120.

Illiteracy in Egypt decreases, but number still high: Official. (2019). Egypt Today. Retrieved from https:// www.egypttoday.com/Article/1/77697/Illiteracy-inEgypt-decreases-but-number-still-high-official\#: : text=A\%20more\%20recent\%20study\%20by,can't \%20read\%20or\%20write

INVEST-GATE. (2016). Ministry of Housing Records EGP 22.2 bn in Sales in 2016. INVEST-GATE. Retrieved from http://invest-gate.me/news/the-ministry-ofhousing-achieves-a-egpp.22--2-bn-profit-in-2016

Madinaty. (2015). About Madinaty. Madinaty. Retrieved from http://www.madinaty.com/Ar/about.aspx

Merche, A., \& Lamprou, S. (2016). Delusional Cairo. In: M. Angélil \& C. Malterre-Barthes (Eds.), Housing Cairo (pp. 58-66). Berlin: Ruby Press.

Metwally, M., \& Abdalla, S. S. (2011). Impact of gated communities on the urban development of new cities in Egypt. Paper presented at the 6th International Conference of the Research Network "Private Urban Governance \& Gated Communities," Istanbul, Turkey.

Mills, A. J., Durepos, G., \& Wiebe, E. (2010). Encyclopedia of case study research. Thousand Oaks, CA: SAGE Publications.

Nabil, J. (2019). Egyptian real estate: Opportunities vs challenges. INVEST-GATE. Retrieved from https://invest-gate.me/features/egyptian-realestate-opportunities-vs-challenges

Nada, M. (2014). The politics and governance of implementing urban expansion policies in Egyptian cities. Égypte/Monde arabe, 11, 145-176.

Next Home Egy. (2019). Heya el hekaya alabet begad keda leeh!! [Why is the story turned so serious!!; Facebook Status Update]. Retrieved from https://www.facebook.com/nexthomegy/photos/ a.438176573192473/859966734346786/?type=3\& theater

Oxford Business Group. (2016). Advertising expenditure on the rise in Egypt. Oxford Business Group. Retrieved from https://oxfordbusinessgroup.com/ analysis/bouncing-back-after-difficult-periodadvertising-expenditure-once-again-rise\#: \{\} : text=Net\%20advertising\%20spend\%20in\%20the,a\% 2012.5\%25\%20rise\%20over\%202014.\&text=For\% 20example\%2C\%20on\%20MBC\%20Masr,5450\% 2D8180)\%20per

Peirce, C. S. (1956). Collected papers of Charles Sanders Peirce. Cambridge, MA: Harvard University Press.

Pettit, H. (2019). The cruelty of hope: Emotional cultures of precarity in neoliberal Cairo. Environment and Planning D: Society and Space, 37(4), 722-739.

Philipsen, K. (2017). Theory building: Using abductive search strategies. In: P. Freytag \& L. Young (Eds.), Collaborative research design (pp. 45-71). Singapore: Springer.

Pollock, D. (2007). The performative" I". Cultural Studies? Critical Methodologies, 7(3), 239-255.
Pollock, D. (2009). Beyond experience. Cultural Studies? Critical Methodologies, 9(5), 636-646.

Rose, G. (2001). Visual methodologies: An introduction to the interpretation of visual materials. Thousand Oaks, CA: SAGE Publications.

Rose, G., Degen, M., \& Melhuish, C. (2014). Networks, interfaces, and computer-generated images: Learning from digital visualisations of urban redevelopment projects. Environment and Planning D: Society and Space, 32(3), 386-403.

Rugh, A. (1984). Family in contemporary Egypt. Syracuse, NY: Syracuse University Press.

Sada el Balad. (2019). Hesham Talaat Moustafa yofage' elgamee' be'oghniat Madinaty le'asala [Hesham Talaat Moustafa suprises everyone with Madinaty's song by Asala; Video File]. Retrieved from https://www. youtube.com/watch?v=Vp1SILt70hQ

Salem, R. (2015). Changes in the institution of marriage in Egypt from 1998 to 2012. In R. Assaad \& C. Krafft (Eds.), The Egyptian labor market in an era of revolution (pp. 162-181). Oxford: Oxford University Press.

Serag, Y. (2015). Impact of politics on the planning of the New Desert City of Toshka in Egypt. Prague: Association of the European Schools of Planing.

Shawkat, Y., \& Hendawy, M. (2016). Myths and facts of urban planning in Egypt. The Buit Environment Observatory. Retrieved from http://marsadomran.info/en/ policy_analysis/2016/11/501/

Shorter, F. C., \& Zurayk, H. C. (1988). The social composition of households in Arab cities: Cairo, Beirut, Amman (Regional Papers No. 31). Cairo: Population Council.

Sims, D. (2003). Sharpening the global development agenda. Understanding slums: Case for the global report on human settlements. The case of Cairo, Egypt. London: Earthscan Publications.

Singerman, D. (2007). The economic imperatives of marriage: Emerging practices and identities among youth in the Middle East (Middle East Youth Initiative Working Paper No. 6). Washington, DC: Brookings Institution.

Support. (2020b). In Merriam-Webster. Retrieved from https://www.merriam-webster.com/dictionary/ support

Talaat Moustafa Group. (2018). Homepage. Talaat Moustafa Group. Retrieved from http://www.talaat moustafa.com/?AspxAutoDetectCookieSupport=1

Watson, V. (2015). The allure of 'smart city'rhetoric: India and Africa. Dialogues in Human Geography, 5(1), 36-39.

Watson, V. (2016). Shifting approaches to planning theory: Global North and South. Urban Planning, 1(4), 32-41.

Watson, V. (2020). Digital visualisation as a new driver of urban change in Africa. Urban Planning, 5(2), 35-43.

Wilson, S. L. (1998). Culture shock! Egypt: A survival guide to customs and etiquette (4th ed.). Tarrytown, NY: Marshall Cavendish Corporation. 
World Bank. (2007). Analysis of housing supply mechanisms, Egypt: Sustainable Development Department Middle East and North Africa. Washington, DC: World Bank.

World Bank. (2008). Arab Republic of Egypt urban sector note. Washington, DC: World Bank.

World Bank. (2012). Reshaping Egypt's economic geography. Washington, DC: World Bank.
Xinhua. (2019). News analysis: Egypt's real estate sector booming amid expectations of more growth: Experts. Xinhuanet. Retrieved from http://www.xinhuanet. com/english/2019-10/15/c_138471815.htm

Yacobi, H., \& Shechter, R. (2005). Rethinking cities in the Middle East: Political economy, planning, and the lived space. Journal of Architecture, 10(5), 499-515.

\section{About the Authors}

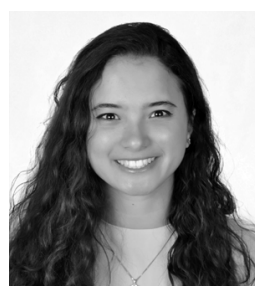

Mennatullah Hendawy is a Research Associate and PhD Candidate at the Chair of Urban Design, TU Berlin. She is also a Visiting Researcher at the Leibniz Institute for Research on Society and Space in Erkner, Germany and an affiliated Assistant Lecturer at the Department of Urban Planning and Design in Ain Shams University in Cairo, Egypt. Mennatullah works on the intersection of urban planning, mediatisation, and justice where she is fascinated by the way knowledge, power, and agency are manifested in and co-construct cities and the public sphere.

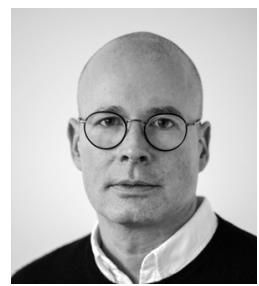

Jörg Stollmann is Professor for Urban Design and Urbanization at the Institute for Architecture, TU Berlin. The chair's work focuses on collaborative and cooperative design processes, mediatisation of planning, and inclusive and climate responsive urban development. Current research projects include Mediatisation Processes in Urban Planning, and SFB/CRC 1265 Re-Figuration of Spaces. Most recent publications: Tiergarten. Landscape of Transgression, Das Kotti Prinzip, and Spatial Commons. Urban Open Spaces as a Resource. Jörg Stollmann graduated from UdK Berlin and Princeton University. 